\title{
DUAL EFFECT OF SYMPATHETIC HYPERFUNCTION ON BLOOD VESSELS IN SPONTANEOUSLY HYPERTENSIVE AND STROKE-PRONE SPONTANEOUSLY HYPERTENSIVE RATS
}

\author{
Man Kondo ', Tatyana Tenkova ${ }^{2}$, and Takashi Fujiwara ${ }^{3}$ \\ ${ }^{1}$ Department of Pathology, Ehime University School of Medicine, Ehime, Japan, ${ }^{2}$ Department of Psychiatry, \\ Washington University Medical School, St. Louis, Missouri, USA, ${ }^{3}$ Laboratory Animal Center, Ehime Univer- \\ sity School ofMedicene, Ehime, Japan
}

\section{SUMMARY}

- The sympathetic nervous system has been considered to be hyperactive from the very beginning after birth in spontaneously hypertensive and stroke-prone spontaneously hypertensive rats. This is a primary factor for the development and maintenance of hypertension via structural and functional alterations of the arteries and the heart. It is. also described that the sympathetic hyperfunction probably play a protective role in necrosis of vascular smooth muscle cells in spontaneously hypertensive and stroke-prone spontaneously hypertensive rats.

\section{INTRODUCTION}

The spontaneously hypertensive rats (SHR) were developed by Okamoto and Aoki (1) for elucidating the pathogenic factors of the human essential hypertension. Three stages were distinguished in relation to the blood pressure: prehypertensive stage (0-30 days after birth), developmental stage (40-90 days after birth) and the established stage (over 90 days after birth). Many biochemical investigations showed abnormal functions of both central and peripheral sympathetic nervous system in SHR and stroke-prone spontaneously hypertensive rats (SHRSP). A dysfunction of the nucleus loci coerulei (2), an increased basal sympathetic tone of the superior cervical ganglia (SCO) (3) and the celiac ganglia (4), and an increased noradrenaline (NA) content in the serum $(5,6)$ and in various tissues (7-9) were described. These authors, however, reported the functional state of the sympathetic nervous system in SHR and SHRSP during the developmental and established stages of hypertension, but not during the prehypertensive stage.

In the following review we describe the morphological studies related to the functional state of the peripheral sympathetic nervous system of SHR and/or SHRSP throughout the prehypertensive to the established stages of hypertension and the effects of the hyperfunction of peripheral sympathetic nervous system on the cardiovascular and cerebrovascular systems.

\section{FUNCTIONAL ACTIVITY OF SUPERIOR CERVICAL GANGLIA AND STELLATE GANGLIA OF SPONTANEOUSLY HYPERTENSIVE RATS}

- Ganglion weight, ganglion cell volume and ganglion cell area

The peripheral sympathetic nervous system regulates blood pressure by modulating the peripheral resistance of the vessels. It has been thought to be one of the most prominent factors in the development of hypertension in SHR. There have been many morphological, physiological and biochemical studies on 
the sympathetic nervous system of SHR after the onset of hypertension (10-14), but only a few studies were carried out on these topics before the development of hypertension. Nerve cell diameter, amount of Nissl granules in the cytoplasm and nucleusto-cytoplasm area ratio, all well-known indicators of nerve cell activity in sympathetic ganglia, have been reported to be higher in SHR than those in normotensive Wistar-Kyoto (WKY) rats. This suggests hyperfunction of the peripheral sympathetic nervous system in SHR (15). These parameters, however, indicate the activity of individual ganglion cells, but not that of whole ganglia.

\section{See Editorial on page 5}

Measurement of ganglion weight per body weight, and morphometrically examined ganglion cell volume and the relative area of ganglion cells in SCG and stellate ganglion (SG) of SHR, younger than 30 days of age and comparison to those of age-matched WKY rats were required (16). These authors showed that: (;') the ganglion weight/body weight ratios of SHR are significantly larger compared to those of WKY rats, within groups aged 30 days, and $(/ ; ')$ the ganglion cell volume and the relative area of ganglionic cells in both ganglia of SHR are significantly larger than those of age- matched WKY rats. These data suggest that the functional state of the whole SCG and SG is significantly higher in SHR than that in WKY rats already before the development of hypertension.

\section{- Protein and neurotransmitter synthetic activity of the ganglia}

Protein and catecholamine synthetic activities of ganglion cells of SCG and SG of SHR during the prehypertensive stage have been examined by light microscopic autoradiography with ${ }^{3} \mathrm{H}$ lysine and ${ }^{3} \mathrm{H}$-DOPA, respectively $(17,18)$. Silver grains representing toe localization of the labeled ${ }^{3} \mathrm{H}$-lysine and ${ }^{3} \mathrm{H}$-DOPA over the cytoplasm of ganglion cells in the SCG and SG have been counted in the same photographic magnifications. Significantly more silver grains over ganglion cells in SHR were observed as compared to age-matched WKY rats, using various incorporation times after injection of ${ }^{3} \mathrm{H}$-lysine, in newborn and 30 days after birth groups. The increased incorporation of the label in both SCG and SG was more marked in newborn animals than 30 days old animals. These results confirmed that a hypersynthesis of protein in SCG and SG is present in SHR immediately after birth. Intravenously administered ${ }^{3} \mathrm{H}$-DOPA is incorporated by nerve cells and rapidly metabolized intracellularly to catecholamines, such as dopamine, noradrenaline and adrenaline (19). Significantly greater number of silver grains were seen over ganglion cells of SCG and SG in SHR compared to those of age-matched WKY rats, using various incorporation times after injection of 'H-DOPA in age groups of 0 and 10 days (18). In newborn SHR, the sympathetic gan- glion cells synthesized a larger amount of catecholamines which were transported or released more rapidly than in the SG cells of WKY rats. Hypersynthesis of catecholamine in the sympathetic ganglia in SHR has been established in this experiment. A summary of these morphometric analyses on protein and neurotransmitter synthetic activity of SCG and SG is given in Table 1. The total functional activity of SCG and SG as measured in these experiments was significantly higher in SHR than in WKY rats in the prehypertensive stage.

\section{- Noradrenergic innervation of the middle cerebral and coronary arteries}

The distribution of noradrenergic nerve fibers in the middle cerebral and coronary arteries of SHRSP has been examined by several authors to estimate the effect of SCG and SG hyperfunction. The distribution density of perivascular sympathetic nerve fibers in SHR has been investigated in various peripheral arteries such as the mesenteric (20), jejunal (21) and caudal arteries (22) in the prehypertensive (23-25), developmental and established stages $(26,27)$ of hypertension, using fluorescence microscopy (26), transmission (28) and scanning (29) electron microscopy. The glyoxylic acid method for the staining of fluorescent noradrenergic nerve fibers in whole mount preparations was applied $(30,31)$. The distribution densities of noradrenergic nerve fibers in the distal portions of the middle cerebral artery (Fig. 1) and in the coronary artery from the prehypertensive to the established hypertensive stage of SHRSP were significantly higher than those of age-matched WKY rats. The difference in the density of nerve fibers between SHRSP and WKY rats was higher in the prehypertensive stage than that in the established hypertensive stage.

Table 1. A comparison behveen spontaneously hypertensive rats (SHR) and Wistar-Kyoto (IVKY) rats in functional activity of superior cervical ganglia (SCG) and stelatte ganglia (SG)

\begin{tabular}{|c|c|c|c|c|c|c|}
\hline \multirow{2}{*}{ Days after birth } & \multicolumn{2}{|c|}{0} & \multicolumn{2}{|c|}{10} & \multicolumn{2}{|c|}{30} \\
\hline & SCG & SG & SCG & SG & SCG & SG \\
\hline Relative weight $^{1}$ & $\uparrow$ & $\rightarrow$ & $\uparrow$ & $\uparrow$ & $\uparrow$ & $\uparrow$ \\
\hline Ganglion cell volume & $\uparrow$ & $\uparrow$ & $\uparrow$ & $\uparrow$ & $\rightarrow$ & $\rightarrow$ \\
\hline Relative area ${ }^{2}$ & $\uparrow$ & $\uparrow$ & $\uparrow$ & $\uparrow$ & $\rightarrow$ & $\rightarrow$ \\
\hline Protein synthesis & $\uparrow$ & $\uparrow$ & $?$ & $?$ & $\uparrow$ & $\uparrow$ \\
\hline Neutotransmitter synthesis & $\uparrow$ & $\uparrow$ & $\uparrow$ & $\uparrow$ & $\uparrow$ & $\rightarrow$ \\
\hline Total activity & $\uparrow \uparrow$ & $\uparrow \uparrow$ & $\uparrow \uparrow$ & $\uparrow \uparrow$ & $\uparrow$ & $\uparrow$ \\
\hline
\end{tabular}



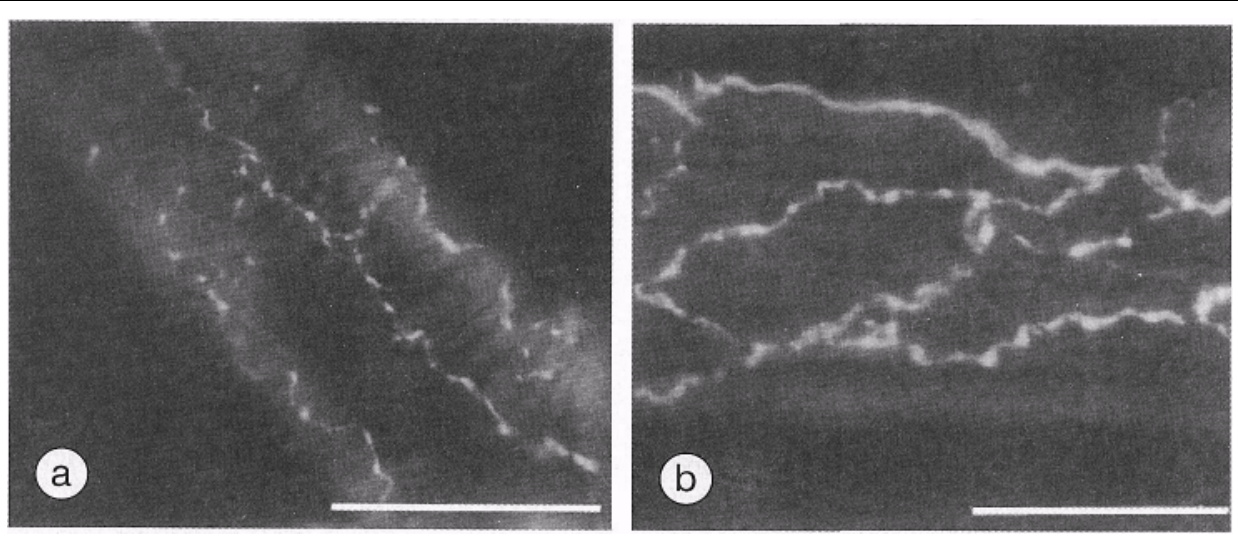

Figure 1. Photomicrographs showing noradrenergic nerve fibers of the distal portion of the middle cerebral arteries of 180-day-old WKY (a) and SHRSP (b). Bars, 30 juin.

Increased sympathetic innervation of the distal portion of middle cerebral artery and of the coronary artery of SHRSP was assumed to be caused by hyperfunction of SCO and /or SG (1618), because the perivascular sympathetic nerves innervating the major cerebral arteries originate from SCG $(32,33)$ and those innervating the coronary arteries originate from SG. Hyperfunction of SCG and SG in SHRSP may promote the development, elongation and branching of nerves supplying these arteries.

\section{- Noradrenergic innervation of the heart}

Although there were many data on the NA content in the heart of SHR from fetus to adult, no definite conclusion could be obtained. While some biochemical studies reported that NA levels in the heart in SHR and SHRSP were lower (9, 34-37) or not higher $(38,39)$ than those of WKY rats, others reported that NA content in the heart in SHR was greater than that in WKY rats (7). Nakamura et al (40) showed data that NA content in the heart was not significantly different between SHR and WKY rats at 6 weeks of age, but was lower in SHR than in WKY rats at 12 weeks of age. Watanabe et al (8), however, reported that there was no difference in NA content in the fetal heart between SHR and WKY rats, but NA content was higher in the heart of 16-week-old SHR than that of age-matched WKY rats. According to Adams et al (41), sympathetic activity was higher in SHR than in WKY rats in the left ventricle through most of the period between 4 and 50 weeks of age.

The noradrenergic nerve fiber density in the heart of SHRSP and WKY rats has been studied, using the glyoxylic acid method for staining frozen sections of $\mathrm{m}\}^{\mathrm{r}}$ ocardium and whole mount preparations of the subepicardium (42). The density of noradrenergic nerve fibers of the subepicardium of the right and left ventricles was higher in SHRSP as compared to that of WKY rats during 10 to 180 days of age. The density of the nerve fibers in myocardium of the right ventricle was higher in SHRSP as compared to that of WKY rats during 30 to 90 days of age. Noradrenergic nerve fiber density of myocardium in the left ventricle and in the ventricular septum of SHRSP was the same as that of WKY rats. These morphometric results suggested that the total amount of NA in the whole heart in SHRSP was larger than that of age-matched WKY rats up to six months after birth.

The hyperinnervation of the heart by noradrenergic nerve fibers in SHRSP is probably the primary change the heart goes through prior to develop an hypertension situation, which may be caused by hyperfunction of SG.

\section{EFFECTS OF SYMPATHETIC HYPERINNERVATION ON THE BLOOD VESSELS AND THE HEART OF STROKE- PRONE SPONTANEOUSLY HYPERTENSIVE RATS}

\section{- $\quad$ Blood vessels}

Sympathetic nerves are known to affect vascular smooth muscle cells (SMC), both through direct, rapid action (43), and longterm regulatory and trophic effects $(44,45)$. In SHRSP, the enhanced perivascular nerves may directly produce intensified vasoconstrictionby the increased NA release from their terminals, as is indicated by electric or $\mathrm{K}^{\mathrm{f}}$-stimulation (46-49), resulting in an increase or the maintenance of peripheral resistance. Sympathetic hyperinnervation of the blood vessels in SHRSP during the prehypertensive stage may, through trophic effects, provoke an elevation in protein synthesis in vascular SMC (50) and an augmentation of the arterial wall mass resulted from medial SMC hypertrophy (51-53) and/or hyperpla- 
sia (54-56), although enhanced SMC proliferation is also reported to be genetically determined $(54,57)$. The thickened arterial media in the prehypertensive $(23,58)$ and established hypertensive stage (59) may become hyperreactive to contractile stimuli (60). In addition, vascular hypeiinnervation may also control the membrane properties of vascular SMC (61), which can induce supersensitivity to catecholamines $(49,62$, 63). Thus the sympathetic hyperinnervation of blood vessels in SHRSP may produce structural and functional alterations in SMC (64) which tend to occlude the vascular lumen in resistant vessels. Therefore they cause an increase in peripheral resistance, an elevation of the blood pressure in the prehypertensive and developing stages of hypertension, and contribute to the maintenance of hypertension in the established stage.

From studies of noradrenergic nerve density it is concluded that hyperinnervation may play an important role in the development of hypertension in SHR and SHRSP (30). This is supported by the fact that the rise in blood pressure was effectively suppressed by sympathectomy in newborn SHR $(55,65-67)$.

\section{- Heart}

Sympathetic nerve fibers are involved in the development of cardiac muscle hypertrophy through a-adrenoceptors (68-70). Several studies have demonstrated that the a-adrenergic nerves stimulate protein synthesis of cardiocytes (68) and increase their size (71-73). Therefore, the higher density of the noradrenergic nerve fibers in SHRSP compared to that of age-matched WKY rats may cause heart hypertrophy in SHRSP due to a primary alteration of the heart at the prehypertensive stage (74, 75). At the established hypertensive stage in SHRSP, the cardiocytes become further hypertrophied by high blood pressure as a secondary factor, because such a mechanical stretch stimulates the cardiocyte protein synthesis $(76,77)$. On the other hand, the complete abolition of the sympathetic activity in 4week-old SHR prevented the development of cardiac hypertrophy (77). These data suggested the leading role of noradrenergic innervation in heart hypertrophy. Cardiocytes hypertrophy occurring as a primary and secondary change of the heart in SHRSP may in its turn augment cardiac activity, resulting in elevation of blood pressure in the prehypertensive and developmental stages of hypertension and in maintenance of hypertension in established hypertensive stage (77).

\section{STRUCTURAL CHANGES IN THE SMOOTH MUSCLE CELLS OF THE MIDDLE CEREBRAL AND CORONARY ARTERIES IN STROKE-PRONE SPONTANEOUSLY HYPERTENSIVE RAT}

\section{- $\quad$ Middle cerebral artery}

The functional and structural alterations of blood vessels have been reported in SHR and SHRSP $(78,79)$. By scanning electron microscopy (SEM), the proximal portion of the middle cerebral artery of 6-month-old WKY rats has a compact and regular medial layer consisting of spindle-shaped SMC running almost parallel to each other and oriented transversely with respect to the long axis of the vessel. The SMC adventitial surface is smooth. Small pits with a round or elliptical openings are found only sporadically on the cell surface (Fig.2a,b). On the other hand, SMC in 6-month-old SHRSP exhibit a remarkably rough surface texture, though their arrangement is unaltered (Fig.2c,d). At a higher magnification, various structural modifications such as deep invaginations forming many pits and long longitudinal depression or grooves become visible on the surface of SMC in SHRSP (Fig.3). These structural modifications are often clustered, covering almost the whole cell width. Necrotic SMC constitute about $10 \%$ of all medial cells in SHRSP and no necrotic SMC were observed in WKY rats.

By transmission electron microscopy (TEM), SMC of the middle cerebral artery in WKY rats show the typical featur of SMC. In SHRSP, transverse profiles of SMC varied from rounded to irregular, with deep indentation of the plasma membrane. The SMC of SHRSP were surrounded by many layers of basal lamina-like material forming a labyrinth-like network in which electron-lucent amorphous material is found (Fig.4a,b). This finding may be consistent with previous biochemical studies that have demonstrated an increase in connective tissue fibers, collagen (80) and elastin $(80,81)$, in the arterial wall of SHR. Irregularly-shaped SMC contain all the organelles common to vascular SMC (82), indicating their ability to function normally.

\section{- Coronary artery}

By SEM, many pits and gutters are observed on the SMC surface of the coronary artery in both WKY rats and SHRSP at 4 months after birth. The SMC from 6-month-old WKY rats

Figure 2. Scanning electron microscopy images of the adventitial surface of medial smooth muscle cells in the proximal portion of the middle cerebral artery. Low power view of the outermost medial layer in WKY rat. The smooth muscle cellsare oriented transversely with respect to the vessel long axis (a). Smooth muscle cells from WKY rat are spindle-shaped with a smooth surface texture (b). Low power view of the outermost medial layer in SHRSP. Smooth muscle cells remain in a circular arrangement, but exhibit an irregular shape and rough surface texture (c). The smooth muscle cells from SHRSP exhibit a very rough surface texture. Asterisk shows a necrotic cell (d). Bar, 20 fim. x 740(a), Bar, 5 urn. x 2000 (b), Bar, 20 turn, x 900 (c), Bar, 5 fj,m. x 2200 (d). 

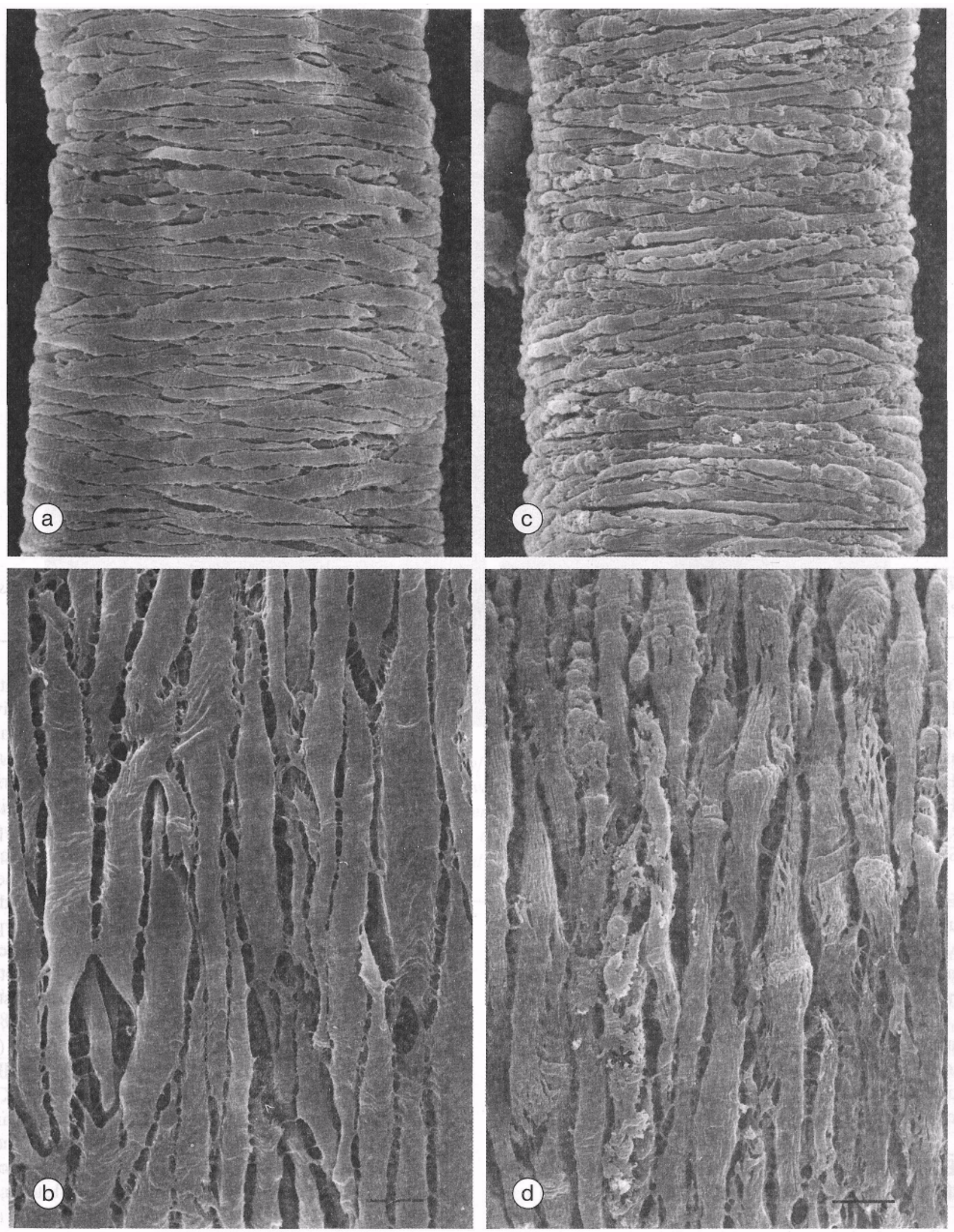


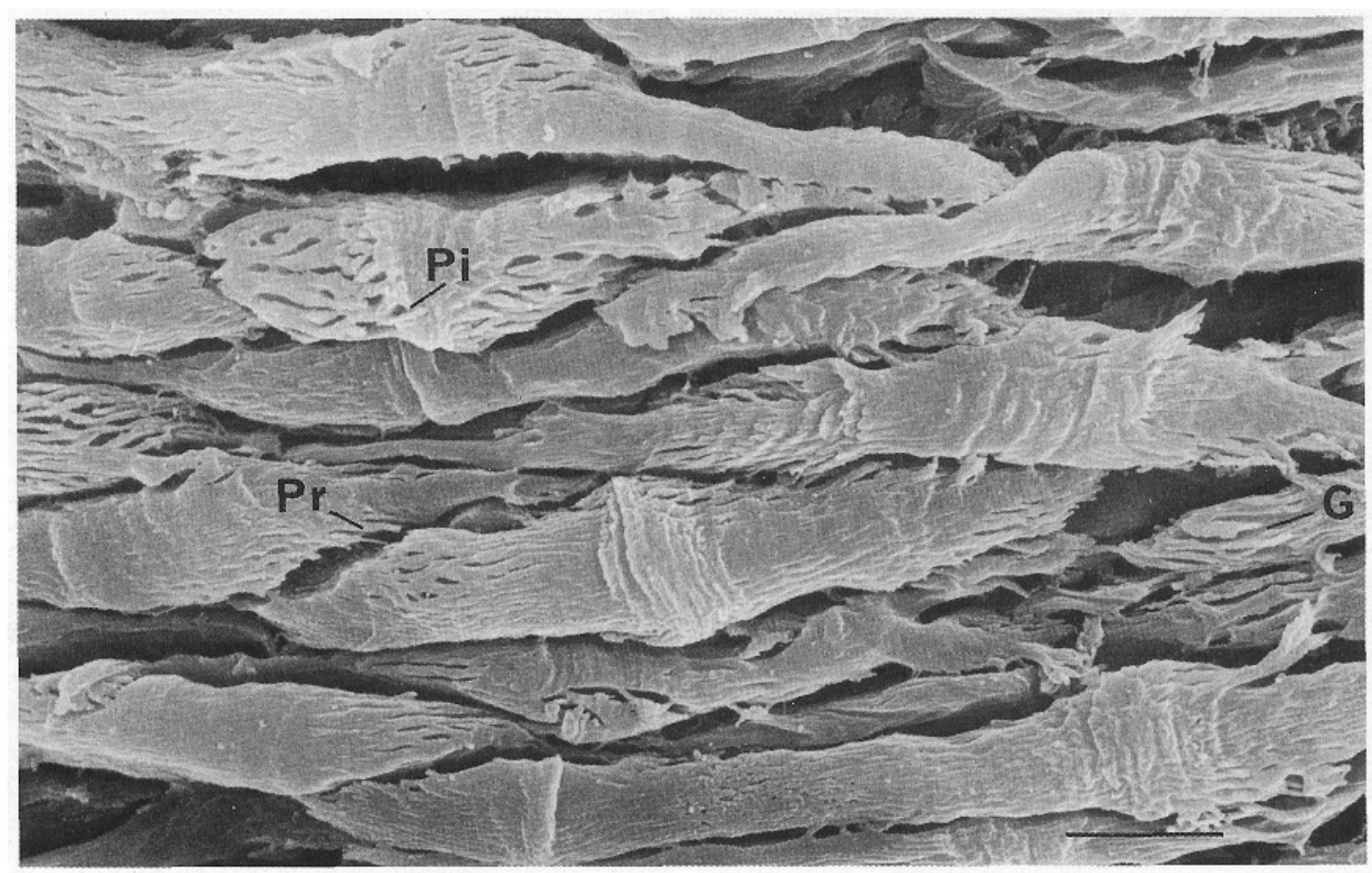

Figure 3. Scanning electron microscopy image of smooth muscle cells of middle cerebral artery from SHRSP. The muscle cells form numerous pits (Pi), grooves $(G)$ and processes $(P r)$. Bar, 5 pm. х 3700.

show rather similar surface texture to that of 4-month-old WKY rats. In contrast with WKY rats, SMC of 6-month-old SHRSP exhibit a remarkably increased number of gutters and pits on the surface. The intercellular space between SMC of 6-monthold SHRSP is increased in width compared to that of 4-monthold SHRSP and WKY rats and 6-month-old WKY rats. No necrotic cells, however, are found in the coronary artery of both SHRSP and WKY rats at these ages.

By TEM, the SMC of 6-month-old SHRSP and WKY rats are irregular in profile with deep indentations of the plasma membrane. They are surrounded by many layers of basal laminalike material,. and large amount of collagen fibrils and fibrous matrix substances are observed between the SMC.

Taken together, the morphological alterations of vascular SMC of middle cerebral and coronary arteries in SHRSP may be adaptive changes to increased tension of the arterial wall in severe hypertension $(83,84)$.

\section{PROTECTIVE ROLE OF SYMPATHETIC}

HYPERINNERVATION IN NECROSIS OF VASCULAR SMOOTH MUSCLE CELLS

- Sympathetic hyperinnervation of blood vessels in SHR and SHRSP has an important role in the development of hypertension. On the other hand, it may play a protective role against stroke due to a trophic effect on the vascular wall (85). Relation between the noradrenergic nerve fiber density and the structure of SMC in the middle, anterior cerebral arteries and in the ophthalmic artery, and the coronary artery, are investigate in both developmental and established stage of hypertension in SHRSP $(86,87)$. More than $10 \%$ of SMC in the proximal portion of the middle cerebral artery (86) and the distal portion of the anterior cerebral artery (unpublished data) of SHRSP become necrotic at the established stage of hypertension. These arteries were innervated by noradrenergic fibers of the same distribution density as those in WKY rats (30).' However, a few or no necrotic SMC are found in the distal portion of the middle cerebral artery (unpublished data), in the ophthalmic artery (87) and in the coronary artery (31) of SHRSP in the established stage of hypertension and all blood vessels were more heavily innervated than those in WKY rats. The difference in the occurrence of necrosis of vascular SMC may be attributed to the difference in nerve density. The latter suggests that sympathetic hyperinnervation may protect SMC from necrosis caused by the great tangential wall stress, which is associated with chronic hypertension. Such a kind of protective role of sympathetic nerves against SMC necrosis (and 

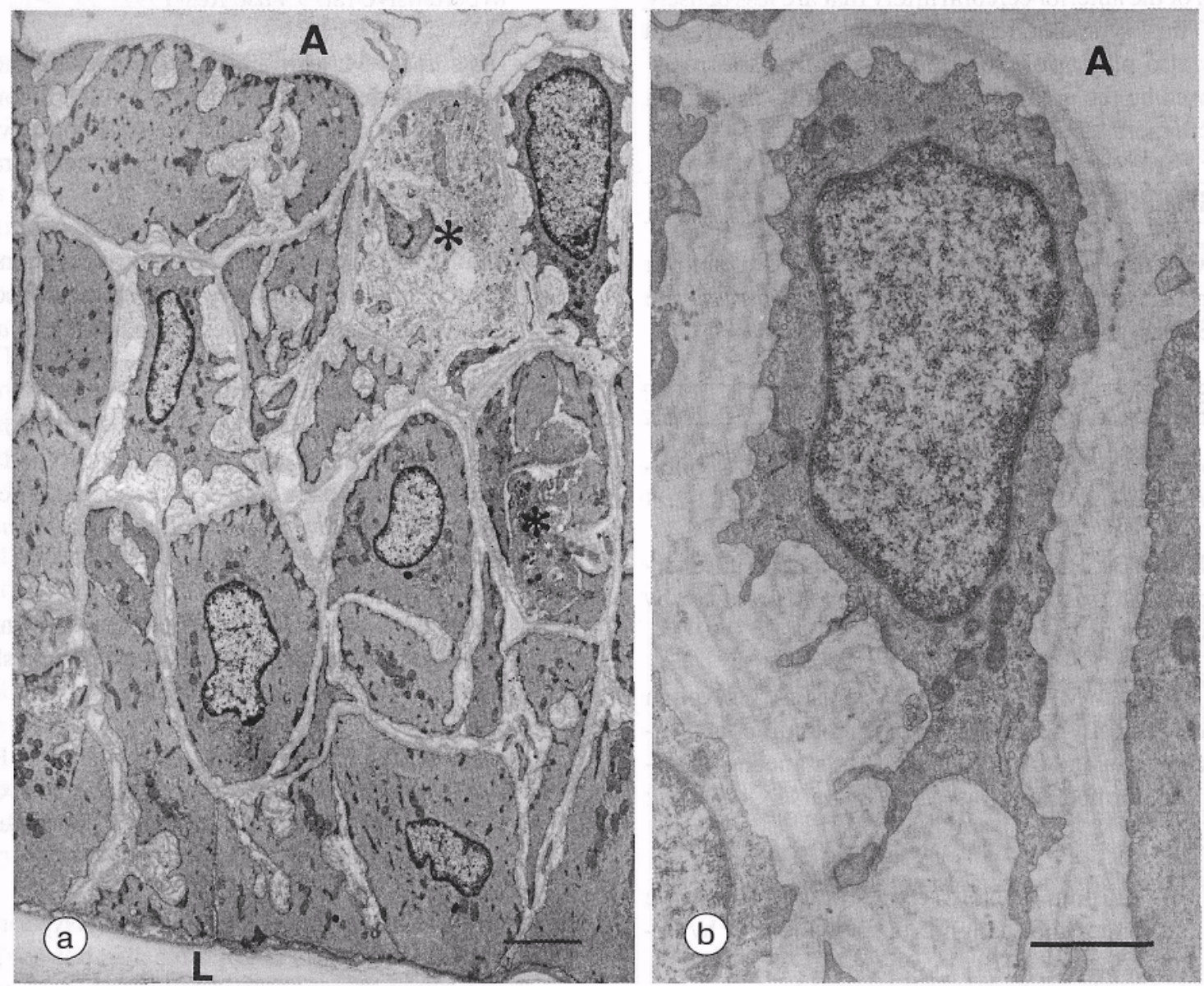

Figure 4. Transmission electron micrographs of the media of proximal portion of SHRSP middle cerebral arteries sectioned parallel to the vessel long axis. The media consists of variously shaped smooth muscle cells, some are rounded and others are irregular with deep imaginations of the plasma membrane. Necrotic cells are depicted (asterisks). A - adventitial surface, L - lumlnal surface (a). Smooth muscle cell from the outermost medial layer exhibits an irregular profile and is surrounded by multiple layers of basal lamina-like material (b). Bar, 2 [im. ${ }^{\times} 4900$ (a). Bar, 1 /j.m. ${ }^{\times} 16000$ (b).

apoptosis ?) may be of a clinical value, since primary rupture of the cerebral arteries has been reported to be caused by "arteriosclerosis" accompanied by degeneration of the medial $\operatorname{SMC}(88,89)$.

\section{CONCLUSION}

- The relative ganglion weight, ganglion cell volume, relative ganglion cell area and protein and catecholamine synthetic activities of SCO and SG at prehypertensive stage of SHR are greater compared to those of age-matched WKY rats, suggesting a hyperfunction of SCO and SG in SHR before the hypertension development. The densities of perivascular norad- renergic innervation in the distal portion of middle cerebral artery, the anterior cerebral, the ophthalmic and the coronary arteries and the heart, which are innervated by SCG or SG, are higher in SHRSP than those in WKY rats during the prehypertensive stage to the established hypertensive stage. Sympathetic hyperinnervation both in arteries and heart from SHR and SHRSP in the prehypertensive stage may have a leading role in development of hypertension, through SMC hypertrophy and hyperplasia and SMC hypersensitivity to NA.

Few necrotic SMC are seen in the densely innervated distal portion of the middle cerebral artery, the ophthalmic and the coronary arteries. On the other hand, many necrotic SMC are seen 
in the proximal portion of the middle cerebral artery and the distal portion of the anterior cerebral artery that are less densely innervated. Thus, sympathetic hyperinnervation in SHR and SHRSP may also play a role to protect SMC from necrosis, which is caused by the great tangential wall stress associated with chronic hypertension.

\section{ACKOWLEDGEIYIENTS}

- We wish to thank Ms Miho Terada, Mr Daizaburou Shimizu, Mr Kazunari Oono and Mr Kenichi Okugawa for the excellent technical assistance.

\section{REFERENCES}

1. Okamoto K, Aoki K. Development of a strain of spontaneously hypertensive rats. Jpn Circ J 1963; 27: 282-293

2. Doba N, Reis D J. Role of central and peripheral adrenergic mechanisms in neurogenic hypertension produced by brainstem lesions in rat. Circ Res 1974; 34: 293-391

3. Alho H, Partanen M, Koistinaho J, Vaalasti A, Hervonen A. Histochemically demonstrable catecholamines in sympathetic ganglia and carotid body of spontaneous hypertensive and normotensive rats. Histochemistry 1984; 80:

$1 \quad 457-462$

4. Lutold BE, Karoum F, Neff NH. Deficient dopamine metabolism in the celiac ganglion of spontaneously hypertensive rats. Circ Res 1979; 44: 467-471

5. Nagaoka A, Lovenberg W. Plasma norepinephrine and dopamine-p'-hydroxylase in genetic hypertensive rats. LifeSci 1976; 19:29-34

6. Pac CH. Plasma adrenaline and noradrenaline concentration of the spontaneously hypertensive rat. Jpn Heart J 1981; 22: 987-995

7. Head RJ, Cassis LA, Robinson RL, Westfall DP, Stitzel RE. Altered catecholamine contents in vascular and nonvascular tissue in genetically hypertensive rats. Blood Vessels 1985; 22: 196-204

8. Watanabe K, Shibata A, Wakabayashi H, Shimada K, Tsuchihashi H, Kinami J et al. Changes in cardiac aland [31-adrenergic receptors and calcium ion-binding sites in the fetal myocardium of spontaneously hypertensive rat (SHR). JPharmacobiodyn 1991; 14: 182-186 :

9. Mano M, Jeffreson S, Head RJ. Vascular, ganglia and cardiac catecholamine disposition in the spontaneously hypertensive rat and in the stroke-prone spontaneously hypertensive rat. J Vase Res 1992; 29: 8-12

10. Matsumoto M. Morphological studies on the autonomic nervous system of hypertensive rats. IV. Fluorescence microscopical observation on the superior cervical sympathetic ganglia of spontaneously hypertensive rats. Jpn Circ .71969; 33: 411-416

11. Gianutsos G, Moore KE. Epinephrine contents of sympathetic ganglia and brain regions of spontaneously hypertensive rats of different ages. ProcSocExpBiolMed 1978 158: $45-49$

12. Judy WV, Watanabe AM, Murphy WR, Aprison BS, Yu P-L. Sympathetic nerve activity and blood pressure in normotensive backcross rats genetically related to the spontaneously hypertensive rat. Hypertension 1979; $598-604$

13. Tsuda K, Kuchii M, Kusuyama Y. Neurotransmitter release and vascular reactivity in spontaneously hypertensive rats. Jpn Circ J 1984; 48:1263-1269

14. Lee RMKW, CoughlinMD, Cheung DWT. Relationship between sympathetic innervation, vascular changes and hypertension in the spontaneously hypertensive rat. $J$ Hypertens 1986; 4 (Suppl 3): S81-S83

15. Peruzzi D, Hendley ED, Forehand CJ. Hypertrophy of stellate ganglion cells in hypertensive, but not hyperactive rats. AmJPhysiol 1991; 261: R979-R984

16. Kondo M, Terada M, Shimizu D, Fujiwara T, Tabei R. Morphometric study of the superior cervical ganglia of spontaneously hypertensive rats during the prehyper tensive stage. VirchowsArch B 1990; 58: 371-376

17. Kondo M. Autoradiographic study of ${ }^{3} \mathrm{H}$-lysine uptake byl superior cervical and stellate ganglia in prehypertensivel spontaneously hypertensive rats. VirchowsArch B 1986; 52: 299-304

18. Kondo M. Autoradiographic study of' H-DOP A uptake by superior cervical and stellate ganglia of spontaneously hypertensive rats during the prehypertensive stage. VirchowsArch B 1987; 54:190-193

19. Nutt J, Fellman J. Pharmacokinetics of levodopa. Clin Neuropharmacol 1984; 7:35-49

20. Lee RMKW, Triggle CR, Cheung DWT, Coughlin MD. Structural and functional consequence of neonatal sympa- 
thectomy on the blood vessels of spontaneously hypertensive rats. Hypertension 1987; 10: 328-338

21. Ichijima K. Morphological studies on the peripheral small arteries of spontaneously hypertensive rats. Jpn Circ J $1969 ; 33: 785-812$

22. Cassis LA, Stitzel RE, Head RJ. Hypernoradrenergic innervation of the caudal artery of the spontaneously hypertensive rat: An influence upon neuroeffector mechanisms. Am Soc Pharmacol Exp Ther 1985; 234: 792-803

23. Scott TM, Pang SC. The correlation between the development of sympathetic innervation and the development of medial hypertrophy in jejunal arteries in normotensive and spontaneously hypertensive rats. J Auton Nerv Syst 1983; 8: 25-32

24. Dhital KK, Gerli R, Lincoln J, Milner P, Tanganelli P, Weber $\mathrm{G}$ et al. Increased density of perivascular nerves to the major cerebral vessels of the spontaneously hypertensive rat: differential changes in noradrenaline and neuropeptide Y during development. Brain Res 1988; 444: $33-45$

25. Kawamura K, Ando K, Takebayashi S. Perivascular innervation of the mesenteric artery in spontaneously hypertensive rats. Hypertension 1989; 14: 660-665

26. Lee TJ-F, Saito A. Altered cerebral vessel innervation in the spontaneously hypertensive rat. Circ Res 1984; 55: $392-403$

27. Lee TJ-F, Saito A. Altered cerebral vessel innervation in spontaneously hypertensive and renal hypertensive rats. JHypertens 1986; 4(Suppl 3): S201-S203

28. Lee RMKW, Forrest JB, Garfield RE, Daniel EE. Ultrastructural changes in mesenteric arteries from spontaneously hypertensive rats. A morphometric study. Blood Vessels 1983; 20: 72-91

29. Chaldakov GN, Nara Y, Horie R, Yamori Y. A new view of the arterial smooth muscle cells and autonomic nerve plexus by scanning electron microscopy in spontaneously hypertensive rats. Exp Pathol 1989; 36:181-184

30. Kondo M, Miyazaki T, Fujiwara T, Yano A, Tabei R. Increased density of fluorescent adrenergic fibers around the middle cerebral arteries of stroke-prone spontaneously hypertensive rats. Virchows Arch B 1991; 61: 117-122

31. Kondo M, Fujiwara T, Miyazaki T, Terada M, Tabei R.
Noradrenergic hyperinnervation may inhibit necrosis of coronary arterial smooth muscle cells in stroke-prone spontaneously hypertensive rats. Virchows Arch 1996; In press

32. Kobayashi S, Tsukahara S, Sugita K, Nagata T. Adrenergic and cholinergic innervation of rat cerebral arteries. Histochemistry 1981; 70: 129-138

3 3. Schon F, Alien JM, Yeats JC, Alien YS, Ballesta J, Polak $\mathrm{JM}$ et al. Neuropeptide Y innervation of the rodent pineal gland and cerebral blood vessels. Neurosci Lett 1985; 57: 65-71

34. Johnson EM, Macia RA. Unique resistance to guanethidine-induced chemical sympathectomy of spontaneously hypertensive rats. A resistance overcome by treatment with antibody to nerve growth factor. Circ Res 1979; 45: $243-249$

3 5. Howes LG, Summers RJ, Louis WJ. The influence of age and sex on cardiac, renal and caudal artery catecholamine content in spontaneously hypertensive (SHR) and WistarKyoto (WKY) rats. J Auton Pharmacol 1986; 6:171-180

36. PahorM, Giudice PL, Bernabei R, Gennaro MD, Pacifici L, Ramacci MT et al. Age-related increase in the incidence of ventricular arrhythmias in isolated heart from spontaneously hypertensive rats. Cardiovasc Drug Ther 1989; 3: 163-169

37. Wocial B, Chodakowska J, Zukowska-Grojec Z, Rutczynski M, Boratynski W. Tissue catecholamine concentrations in spontaneously hypertensive rats. Acta PhysiolPol 1977; 28: 303-312

38. Lee RMKW, Borkowski KR, Leenen FHH, Tsoporis J, Coughlin M. Combined effect of neonatal sympathectomy and adrenal demedullation on blood pressure and vascular changes in spontaneously hypertensive rats. Circ Res 1991; 69: 714-721

39. Donohue SJ, Stitzel RE, Head RJ. Time course of changes in the norepinephrine content of tissue from spontaneously hypertensive and Wistar-Kyoto rats. / Pharmacol Exp Ther 1988; 245: 24-31

40. Nakamura K, Gerold M, Thoenen H. Genetically hypertensive rats: relationship between the development of hypertension and the changes in norepinephrine turnover of peripheral and central adrenergic neurons. Arch Pharmacol 1971;271: 157-169 
41. Adams MA, Bobik A, Korner PI. Differential development of vascular and cardiac hypertrophy in genetic hypertension: relation to sympathetic function. Hypertension 1989; 14: 191-202

42. Kondo M, Fujiwara T, Tabei R. Noradrenergic hyperinnervation in the heart of stroke-prone spontaneously hypertensive rats (SHRSP). HypertensRes 1996;19: 6973

43. Burnstock G, Griffith SG, Sneddon P. Autonomic nerves in the precapillary vessel wall. / Cardiovasc Pharmacol 1984; 6 (Suppl 2): 344-353

44. Head RJ. Hypernoradrenergic innervation: its relationship to functional and hyperplastic changes in the vasculature of the spontaneously hypertensive rat. Bloodvessels 1989; 26: $1-20$

45. Dimitriadou V, Aubineau P, Taxi J, Seylaz J. Ultrastructural changes in the cerebral artery wall induced by longterm sympathetic denervation. Blood Vessels 1988; 25: $122-143$

46. Galloway MP, Westfall TC. The release of endogenous norepinephrine from the coccygeal artery of spontaneously hypertensive and Wistar-Kyoto rats. CircRes 1982; 51 : 225-232

47. Masuyama Y, Tsuda K, Kusuyama Y, Hano T, Kuchii M, Nishio I. Neurotransmitter release, vascular responsiveness and their calcium-mediated regulation in perfused mesenteric preparation of spontaneously hypertensive rats and DOCA-salt hypertension. JHypertens 1984; 2(Suppl 3): $99-102$

48. Tsuda K, Kuchii M, Nishio I, Masuyama Y. Effects of epinephrine and dopamine on norepinephrine release from the sympathetic nerve endings in hypertension. ./ Hypertens 1986; 4 (Suppl 5): S45-S48

49. Hano T, Rho J. Norepinephrine overflow in perfused mesenteric arteries of spontaneously hypertensive rats. Hypertension 1989; 14: 44-53

50. Kanbe T, Nara Y, Tagami M, Yamori Y. Studies of hypertension-induced vascular hypertrophy in cultured smooth c muscle cells from spontaneously hypertensive rats. Hypertension 1983 ; 5:887-892

51. Eccleston-Joyner CA, Gray SD. Arterial hypertrophy in the fetal and neonatal spontaneously hypertensive rat. Hypertension 1988; 12: 513-518
52. Owens GK, Schwarts SM Alterations in vascular smooth muscle mass in the spontaneously hypertensive rats; Role of cellular hypertrophy, hyperploidy, and hyperplasia. Ore flay 1982; 51: 280-289

53. Miller BG, Connors BA, Bohlen G, Evan AP. Cell and wall morphology of intestinal arterioles from 4- to 6- and 17- to 19-week-old Wistar-Kyoto and spontaneously hypertensive rats. Hypertension 1987; 9: 59-68

54. Mulvany MJ, Baandrup U, Gundersen HJG. Evidence for hyperplasia in mesenteric resistance vessels of spontaneously hypertensive rats using a three-dimensional dissector. CircRes 1985; 57: 794-800

55. Mangiarua El, Lee RM. Morphometric study of cerebral arteries from spontaneously hypertensive and stroke-prone spontaneously hypertensive rats. / Hypertens 1992; 10: $1183-1190$

56. Yang H, Morton W, Lee RMKW, Kajetanowicz A, Forrest JB. Autoradiographic study of smooth muscle cell proliferation in spontaneously hypertensive rats. Clin Sci 1989 76:475-478

57. Hamada M, Nishio I, Baba A, Fukuda K, Takeda J, Ura M et al. Enhanced DNA synthesis of cultured vascular; smooth muscle cells from spontaneously hypertensive rats.' Atherosclerosis 1990; 81: 191-198

58. Karr-Dulline V, Bloomquist El, Beringer T, EI-Bermani AI-W. Arterial morphometry in neonatal and infant spontaneously hypertensive rats. Blood Vessels 1981; 18: 253262

59. Nordborg C, Fredriksson K, Johansson BB. The morphometry of consecutive segments in cerebral arteries of normotensive and spontaneously hypertensive rats. Stroke 1985; 16: 313-320

60. Lee RMKW, Smeda JS. Primary versus secondary struc- $\backslash$ tural changes of the blood vessels in hypertension. Can J Physiol Pharmacol 1985; 63: 392-401

61. Abel PW, Hermsmeyer K. Sympathetic cross-innervation of SHR and genetic control suggests a trophic influence on vascular muscle membranes. CircRes 1981; 49: 13111318

62. Lais LT, Brody MJ. Vasoconstrictor hyperresponsiveness: an early pathogenetic mechanism in the spontaneously hypertensive rat. Eur J Pharmacol 1978; 47: 177-189 
63. Longhurst PA, Stitzel RE, Head RJ. Perfusion of the intact and partially isolated rat mesenteric vascular bed: Application to vessels from hypertensive and normotensive rats. Blood Vessels 1986; 23: 288-296

64. Lee RMKW. Vascular changes at the prehypertensive phase in the mesenteric arteries from spontaneously hypertensive rats. Blood Vessels 1985; 22: 105-126

65. Folkow B, Hallback M, Lundgren Y, Weiss L. The effect of immunosympathectomy on blood pressure and vascular reactivity in normal and spontaneously hypertensive rats. Acta Physiol Scand 1972; 84: 512-523

66. Hart MN, Heistad DD, Brody ML Effect of chronic hypertension and sympathetic denervation on wall/lumen ratio of cerebral vessels. Hypertension 1980; 2: 419-423

67. Sinaiko AR, Cooper MJ, Mirkin BL. Effect of neonatal sympathectomy with 6-hydroxydopamine on the reactivity of the renin-angiotensin system in the spontaneously hypertensive rat. Clin Sci 1980; 59: 123-129

68. Simpson P, McGrath A, Savion S. Myocyte hypertrophy in neonatal rat heart cultures and its regulation by serum and by catecholamines. Circ Res 1982; 51: 787-801

69. Meidell RS, Sen A, Henderson SA, Slahetka MF, Chien KR. al-adrenergic stimulation of rat myocardial cells increases protein synthesis. Am J Physiol 1986; 251: H1076-1084

70. Marino TA, Walter RA, Cobb E, Palasiuk M, Parsons T, Mercer WE. Effect of norepinephrine on neonatal rat cardiocyte growth and differentiation. In Vitro Dev Biol 1990; 26: 229-236

71. Simpson P. Norepinephrine-stimulated hypertrophy of cultured rat myocardial cells is an a 1-adrenergic response. J Clin Invest 1983; 72: 732-738

72. Simpson P. Stimulation of hypertrophy of cultured neonatal rat heart cells through an al-adrenergic receptor and induction of beating through an al- and fi-adrenergic receptor interaction. Evidence for independent regulation of growth and beating. Circ Res 1985; 56: 884-894

73. Long CS, Ordahl CP, Simpson PC. oc-adrenergic receptor stimulation of sarcomeric actin isogene transcription in hypertrophy of cultured rat muscle cells. J Clin Invest 1989; 83: 1078-1082

74. Kawamura K, Kashii C, fmamura K. Ultrastructural changes in hypertrophied myocardium of spontaneously hypertensive rats. Jpn Circ J 1976; 40: 1119-1145

75. Imamura K, Takatsu T, Kashii C, Kawamura K. Cardiac hypertrophy in spontaneously hypertensive rats, ultrastructural cytochemistry of B-hydroxybutyrate dehydrogenase. Jpn Heart J 1977; 18: 581-582

76. Komuro I, Kurabayashi M, Takaku F, Yazaki Y. Expression of cellular oncogenes in the myocardium during the developmental stage and pressure-overloaded hypertrophy of the rat heart. Circ Res 1988; 62: 1075-1079

77. Korner PI, Bobik A, Jennings GL, Angus JA Anderson WP. Significance of cardiac hypertrophy in the development and maintenance of hypertension. J Cardiovasc Pharmacol 1991; 17(Suppl 2): S25-S32

78. Mulvany MJ. Do resistance vessel abnormalities contribute to elevated blood pressure of spontaneously hypertensive rats? A review of the evidence. Blood Vessels 1983; 20: 1-22

79. Winquist RJ, Bohr DF. Structural and functional changes in cerebral arteries from spontaneously hypertensive rats. Hypertension 1983; 5: 292-297

80. Deyl Z, Jelinek J, Macek K, Chaldakov G, Vankov VN. Collagen and elastin synthesis in the aorta of spontaneously hypertensive rats. Blood Vessels 1987; 24: 313-320

81. Greenwald SE, Berry CL. Static mechanical properties and chemical composition of the aorta of spontaneously hypertensive rats: a composition with the effects of induced hypertension. Cardiovasc Res 1978; 12: 364-372

82. Gabella G. An introduction to the structural variety of smooth muscles. In: Bevan JA, Maxwell RA, Shibata S, Fujiwara M, Mohri K, Toda N, editors. Vascular Neuroeffector Mechanisms. 4th International Symposium. Raven Press, New York, 1983; 13-35

83. Folkow B, Hallback M, Lundgren Y, Sivertsson R, Weiss L. Importance of adaptive changes in vascular design for establishment of primary hypertension, studied in man and in spontaneously hypertensive rats. Circ Res 1973; 32-33 (Suppl 1):2-16

84. Nordborg C, Johansson BB. Morphometric study on cerebral vessels in spontaneously hypertensive rats. Stroke 1980; 11: 266-270

85. Sadoshima S, Busija DW, Heistad DD. Mechanisms of 
protection against stroke in stroke-prone spontaneously hypertensive rats. AmJPhysiol 1983; 244: H406-H412

86. Fujiwara T, Kondo M, Tabei R. Morphological changes in cerebral vascular smooth muscle cells in stroke-prone spontaneously hypertensive rats (SHRSP). VirchowsArch B 1990; 58: 377- 382

87. Tenkova T, Kondo M, Fujiwara T, Tabei R, Tsukahara S. Sympathetic hyperinnervation protects vascular smooth muscle cells from necrosis in stroke-prone spontaneously hypertensive rats. VirchowsArch B 1993; 64: 373-377

88. Takebayashi S, Kaneko M. Electron microscopic studies of ruptured arteries in hypertensive intracerebral hemorrhage. Stroke 1983; 14: 28-36

89. Takebayashi S. Ultrastructural morphometry of hypertensive medial damage in lenticulostriate and other arteries. Srtoke 1985; 16: 449-453

Received 25August 1996

Accepted 12 October 1996

For correspondence:

Dr Mari Kondo

Department of Pathology

School of Medicine

Ehime University

Shigenobu

Omen-gun

Ehime 791-02

Japan

Fax: 81 (89) 9644988 